\title{
CYCLIC STRESS STRAIN BEHAVIOUR OF HIGH-MELTING POINT METALS
}

\author{
S.Kong, B.Weiss, R.Stickler - University of Vienna \\ M.Witwer, H.Hödl - Metallwerk Plansee, Reutte
}

Austria

\begin{abstract}
For a detailed characterization of the fatigue behavior of metals, knowledge on the cyclic stress strain response is essential. While extensive results have been published for fcc metals, the data for bcc metals are limited essentially to iron and steels. Comparable data are rarely available for the room-temperature behaviour of the high melting point bcc-metals. In the present investigation the fatigue behavior of specimens machined from Mo and Ta sheet (in as-worked and recrystallized conditions) has been determined by conventional load controlled fatigue tests under axial push-pull loading. The strain rate dependence of the deformation behavior was deduced from room temperature tensile tests. Cyclic stress strain curves were recorded for two test frequencies and the cyclic plastic strain measured over the total loading interval. Of particular significance is the frequency dependence of the cyclic plasticity exhibited at room temperature by these bcc pm-metals in the recrystallized state, above a critical stress amplitude. These effects appear to be of considerable engineering significance and must be taken into account for a comparison of fatigue data taken from various sources.
\end{abstract}

KEYWORDS: mechanical properties, fatigue, cyclic stress strain behaviour, molybdenum, tantalum, sheet material

\section{INTRODUCTION:}

It is well known that the cyclic behaviour of metals depends sensitively on several parameters such as strain rate, temperature, purity, microstructure, etc. These effects are well documented for fcc metals such as $\mathrm{Cu}$ while only limited data can be found in the literature for bcc metals and alloys. Most of such basic studies have been carried out with bcc-Fe single and polycrystalline specimens $(1,2)$ and steels $(3)$. 
Unlike the fcc metals the deformation response of bcc metals shows a strong dependence of the flow stress on the deformation rate and temperature below a critical temperature. This has been attributed to a limited mobility of screw dislocations resulting from their particular extended core structure in bcc metals (1).

Below the critical temperature edge dislocations are more mobile than screw dislocations and dislocation multiplication by bowing is difficult. Furthermore, in this temperature regime slip plane and stress asymmetries have been noticed, leading to an asymmetry in the cyclic response under tension and compression. Above the critical temperature screw and edge dislocations have similar mobilities and the deformation behaviour approaches that of fcc metals.

Very few investigations of the mechanisms governing the fatigue behavior of bcc high melting point metals such as $\mathrm{Ta}$ and $\mathrm{Nb}$ have been published. For high-purity single crystals of $\mathrm{Ta}$ the critical temperature was determined $(4,5)$ as $218^{\circ} \mathrm{C}$ and $121^{\circ} \mathrm{C}$ for strain rates of $6 \times 10^{-3} / \mathrm{s}$ and $2 \times 10^{-5} / \mathrm{s}$, respectively. This behaviour could be related to a dislocation glide mechanism by thermally activated kink pairs peculiar to bcc metals $(4,5)$ below a critical temperature or above a critical strain rate. The critical temperature should also be sensitively affected by the impurity content of the specimen material. Thus, material conditions and experimental parameters are considered to influence markedly the fatigue response at low test temperatures.

In recent years increased interest in the high-tech application of high melting point metals and alloys has stimulated investigations on the fundamental mechanisms of their fatigue response. As part of an extensive research effort to provide basic material data for high melting point metals and alloys, it was the objective of this investigation to present information contributing to the basic understanding of the fatigue response of pure molybdenum and tantalum at room temperature.

Pure Ta and Mo specimens machined from sheet materials in the stress relieved and recrystallized condition were evaluated. The investigation was carried out by sinusoidal fatigue loading under load contol. S-N data, the cyclic stress strain response, and cyclic deformation curves were determined in addition to the determination of the strain-rate effects on tensile properties.

\section{Materials Properties:}

As specimen materials pure Ta and Mo in form of sheet metal were selected. Both metals were tested in the as-worked and in the recrystallized condition. Heat treatment and chemical analysis data are listed in Table 1. 
Table 1: $\quad$ Chemical Composition, Heat Treatment and Properties of Specimen Materials

Composition, (ppm):

Ta: $\quad 160 \mathrm{~W}, 11 \mathrm{Ni}, 25 \mathrm{Fe}, 17 \mathrm{Mo}, 106 \mathrm{O}_{2}, 26 \mathrm{C}$ (all other elements below detection limit)

Mo: $\quad 190 \mathrm{~W}, 30 \mathrm{Fe}, 20 \mathrm{O}_{2}, 15 \mathrm{C}$ (other elements below detection limit)

Conditions:

Ta, sheet metal 2 mm thick:

"Deformed": $83 \%$ rolled

"Recrystallized": deformed $+1200^{\circ} \mathrm{C} / 2 \mathrm{~h}, \mathrm{ASTM}$ grain size 5.5

Mo, sheet metal, $1 \mathrm{~mm}$ thick:

"Stress relieved": cross-rolled, stress relieved $\left(800^{\circ} \mathrm{C} / 1 \mathrm{~h}\right)$

"Recrystallized": deformed $+1200^{\circ} \mathrm{C} / 1 \mathrm{~h}$, ASTM grain size 8-9

Mechanical properties at room temperature: tensile test at $0.5 \mathrm{~mm} / \mathrm{min}$ cross-head speed (totalstrain rate $2.8 \times 10^{-4} / \mathrm{s}$ )

\begin{tabular}{|c|c|c|c|c|c|c|}
\hline Material & $\begin{array}{l}\mathrm{R}_{\mathrm{p} 0.2} \\
\mathrm{MPa}\end{array}$ & $\begin{array}{l}\mathrm{R}_{\mathrm{eH}} \\
\mathrm{MPa}\end{array}$ & $\begin{array}{l}\mathrm{R}_{\mathrm{eL}} \\
\mathrm{MPa}\end{array}$ & $\begin{array}{l}\mathrm{R}_{\mathrm{m}} \\
\mathrm{MPa}\end{array}$ & $\begin{array}{l}\text { A5 } \\
\%\end{array}$ & HV 10 \\
\hline Ta-deformed & 400 & & & 410 & 11 & 162 \\
\hline Ta-recrystallized & & 254 & 165 & 249 & 59 & 79 \\
\hline Mo-stress relieved & 650 & & & 740 & 18 & 260 \\
\hline Mo-recrystallized & & 380 & 356 & 442 & 43 & 192 \\
\hline
\end{tabular}

The tensile properties were determined with standard specimens in a commercial tensile test equipment operated at room temperature with cross-head speed between $0.025 \mathrm{~mm} / \mathrm{min}$ and $250 \mathrm{~mm} / \mathrm{min}$, resulting in specimens with a gauge length of $30 \mathrm{~mm}$ at total-strain rates between $1.4 \times 10^{-5} / \mathrm{sec}$ and $1.4 \times 10^{-1} / \mathrm{sec}$. The test results for both metals in the as-worked and recrystallized conditions are shown in Figs.la and $1 \mathrm{~b},(6,7)$. For the deformed materials the values of yield stress $\left(R_{p 0.2}\right)$ and ultimate tensile stress $\left(R_{m}\right)$ were deduced from the stressstrain curves. The recrystallized materials exhibited a marked upper yield stress $\left(\mathrm{R}_{\mathrm{eH}}\right)$ peak which was strongly strain-rate dependent. The $R_{m}$ values increased with strain rate over the whole interval tested while the $\mathrm{R}_{\mathrm{eH}}$ and $\mathrm{R}_{\mathrm{eL}}$ (lower yield stress) values indicated a maximum at a strain rate of about $3 \times 10^{-3} / \mathrm{sec}$. In this strain rate range the $\mathrm{R}_{\mathrm{eH}}$ values exceeded the corresponding $\mathrm{Rm}$ values. It should be pointed out that the fatigue loading was carried out under comparable mean strain rates. 


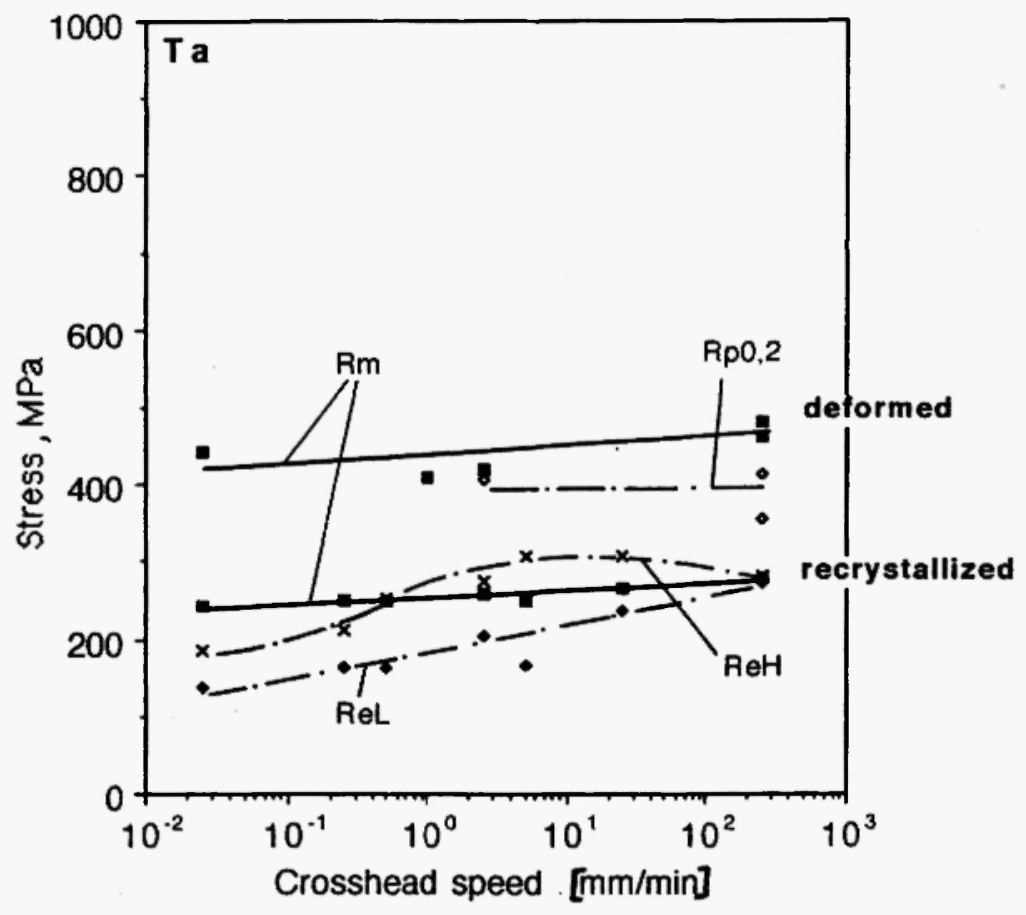

Fig. 1a: Strain rate dependence of tensile properties, Ta-sheet specimens in deformed and recrystallized conditions

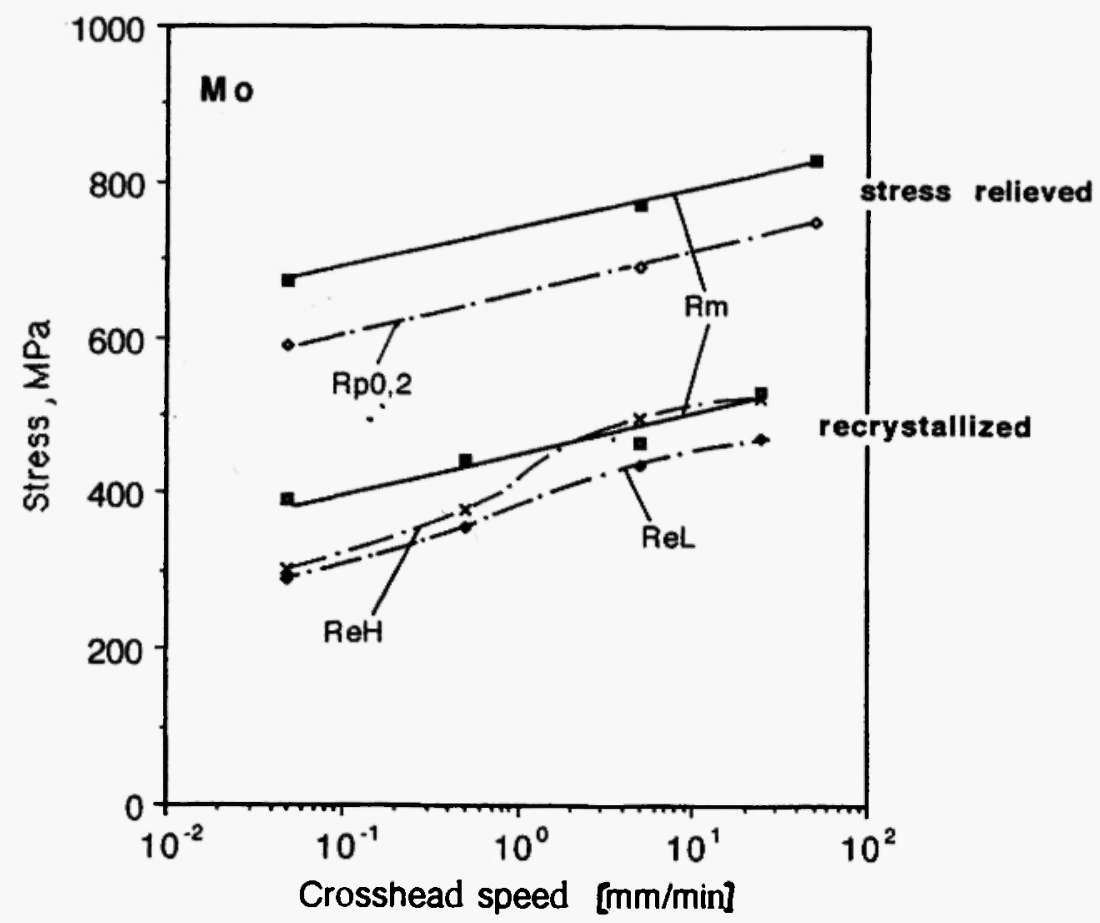

Fig. 1b: Strain rate dependence of tensile properties, Mo-sheet specimens in stress-relieved and recrystallized conditions 
Fatigue experiments:

Specimen Geometry:

For most of the tests hour-glass specimens were machined from the sheet metals ( $2 \mathrm{~mm}$ thickness for Ta, $1 \mathrm{~mm}$ thickness for Mo) and mechanically polished in the gauge section. Strain-gauges were applied in the narrowest region of the gauge length (6mm width) for determination of the strain range. For tests where larger plastic strains were experienced (recrystallized $\mathrm{Ta}$ ), specimens with a parallel gauge section to permit the application of a clip gauge had to be machined. These specimens required utmost care in alignment to minimize buckling at higher loading amplitudes.

Experimental Procedure:

The fatigue tests were performed with a $10 \mathrm{kN}$ servohydraulic test system under sinusoidal stress cycling at room temperature. All tests were carried out under load control at a meticulously controlled zero mean stress, $R=-1$. Since previous investigations have shown a significant effect of the numbers of cycles involved to reach the desired constant load amplitude ("loading ramp"), most of the fatigue tests were started with a loading ramp of $\mathbf{N}_{A}=$ 100 cycles (9). During this ramping the load was step-wise increased by $1 \%$ of the final load amplitude at every zero-transition from compression to tension. Thereafter the cyclic loading was continued at constant stress amplitude.

During the start-up ramp at a cyclic frequency of $0.05 \mathrm{~Hz}$ every hysteresis loop was recorded with a X-Y recorder and simultaneously the data filed in a computerized data acquisition system. After reaching the desired stress amplitude and after about additional 300 cycles, the loading frequency in most experiments was increased to $5 \mathrm{~Hz}$ to reduce the test time to acceptable limits. At suitable intervals the test frequency was lowered again to $0.05 \mathrm{~Hz}$ for only a few loading cycles to record the appropriate hysteresis loop (this testing sequence is indicated in the following by $0.05 \mathrm{~Hz}^{*}$ ). In some tests the data acquisition system was continuously operated during the $5 \mathrm{~Hz}$ tests to reveal the influence of test frequency. A few tests were also continued at $0.05 \mathrm{~Hz}$ to obtain comparable information for low-frequency tests. A set of tests was carried out at $10 \mathrm{~Hz}$ to obtain corresponding data for higher test frequencies. For these tests the loading ramp had to be extended to $N_{A}=1000$ cycles.

The plastic strain rate, approximated as the linearized mean value for the sinusoidal loading, was calculated according to following equation proposed by Mughrabi (1):

$$
\varepsilon_{\mathrm{pl}}=2 \vee \times \Delta \varepsilon_{\mathrm{pl}}
$$

For Ta the calculated strain rate falls between $2 \times 10^{-6} / \mathrm{s}$ and $1 \times 10^{-3} / \mathrm{s}$, and for Mo between $2 \times 10^{-7} / \mathrm{s}$ and $2 \times 10^{-4} / \mathrm{s}$ depending on test frequency and stress amplitude. The results of this investigation showed an unexpectedly large effect of the frequency changes on the plastic strain range. The implication of these findings will be discussed in the following.

In addition to the total-strain and the plastic-strain values, the cyclic-induced creep strain was recorded. The cyclic creep was defined here as the displacement of the center of the hysteresis loop with respect to the zero position at the start of the test. For verification of the creep results the cross-head displacement was continuously recorded with an inductive displacement sensor. 


\section{EXPERIMENTAL RESULTS AND DISCUSSION:}

The S-N data obtained for the various materials and test conditions are summarized in Figs.2ac. These figures clearly show the expected higher fatigue strength of the deformed materials and the effects of test frequency which is more pronounced for the recrystallized materials.

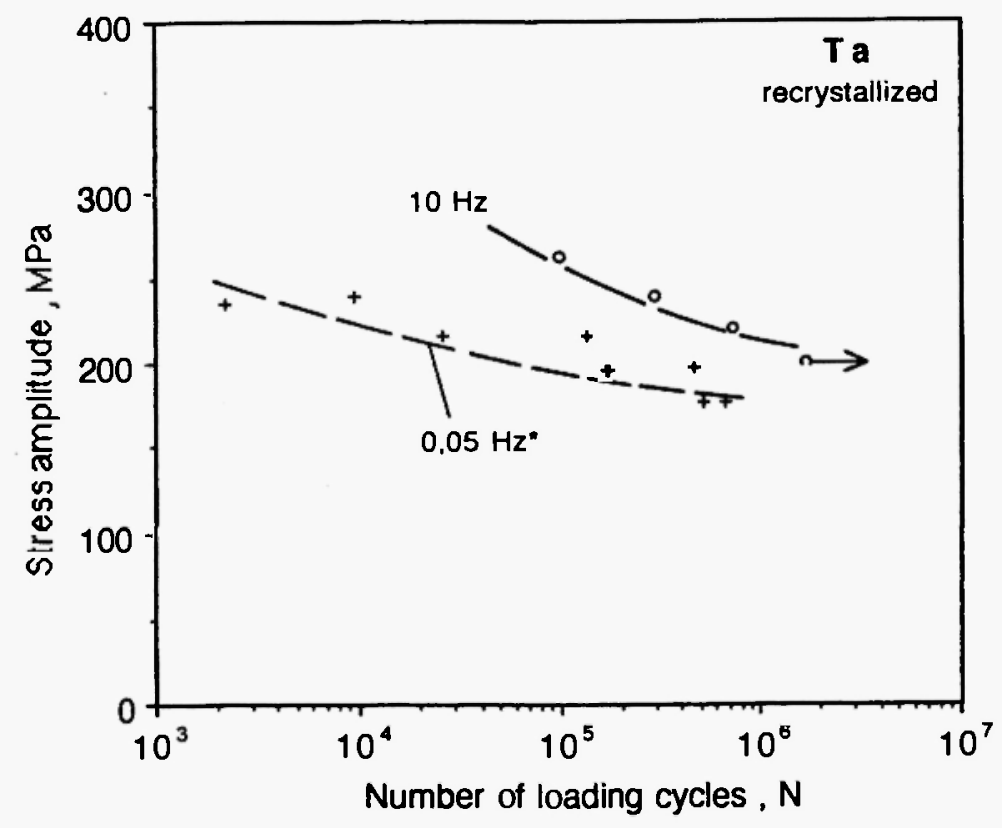

Fig. 2a: S-N curves of recrystallized Ta-specimens at $R=-1$, room temperature and various test frequencies

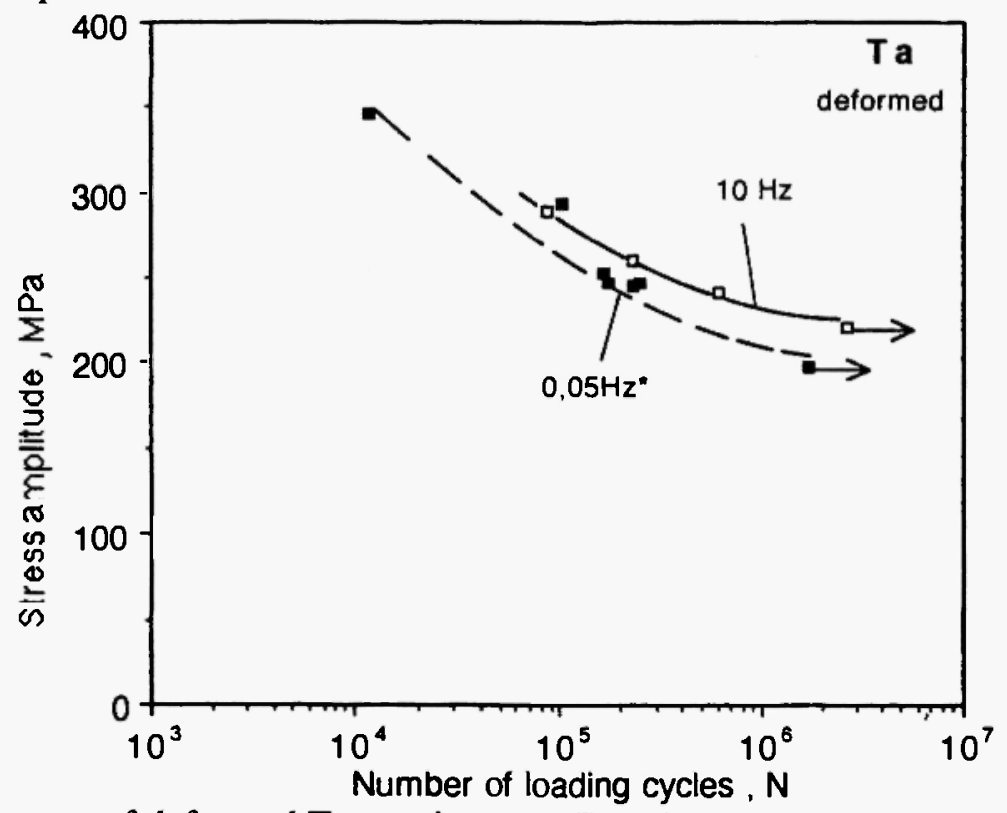

Fig. 2b: S-N surves of deformed Ta-specimens at $R=-1$, room temperature and various test frequencies 


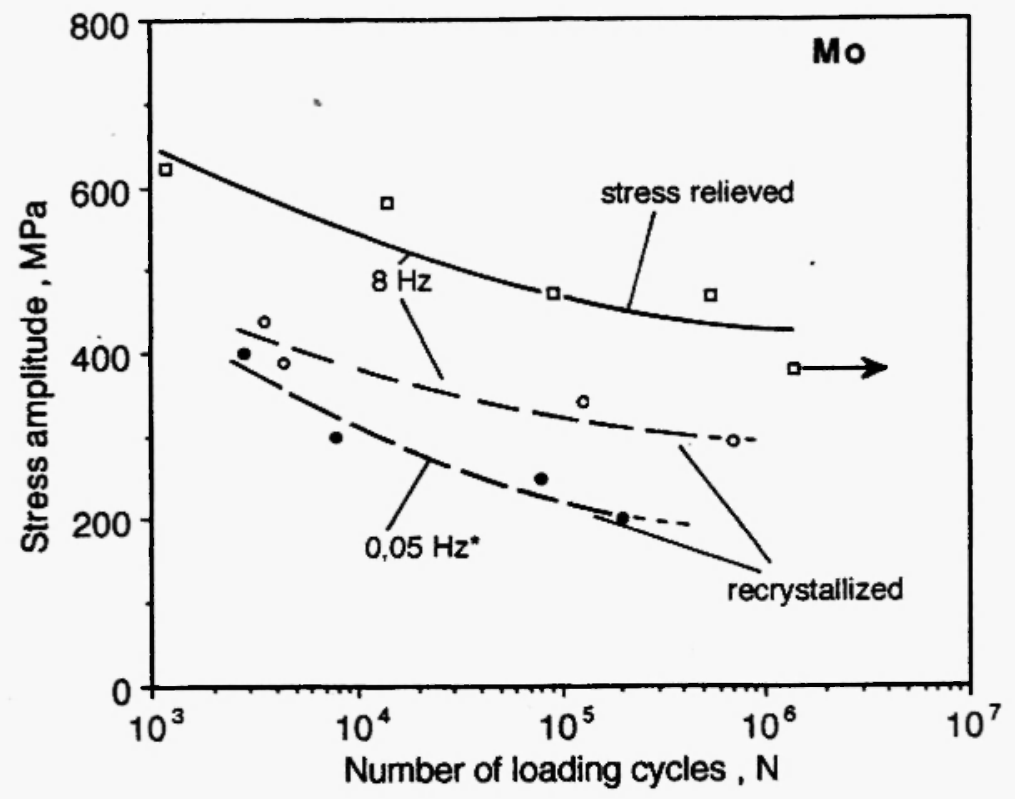

Fig. 2c: S-N curves of stress-relieved and recystallized Mo-specimens at $R=-1$, room temperature and various test frequencies

The increase in stress amplitude during the start-up ramp and its constant value during the subsequent constant amplitude cycling at $216 \mathrm{MPa}$ is shown for a recrystallized Ta specimen in Fig.3a. The related curves for the total strain range and the plastic strain range are given in Fig.3b. From the plastic-strain curves it can be seen that neither pronounced cyclic hardening nor softening occurs for extended numbers of loading cycles (in contrast to observations on $\mathrm{Nb}$ specimens which were reported to exhibit cyclic hardening, probably due to the particular microstructure or impurity content, (8)). Preceding experiments revealed that the extent of the loading ramp does not affect the saturated plastic strain amplitude, at least for deformed Ta.

The plastic-strain response of recrystallized $\mathrm{Ta}$ is shown for several stress amplitudes in Fig.4. For a test frequency of $0.05 \mathrm{~Hz}$ a pronounced increase in the associated plastic strain range can be recognized for stress amplitudes above $180 \mathrm{MPa}$. The data points indicate that the intermittent change in testing frequency (recording of the hysteresis loops at $0.05 \mathrm{~Hz}$ and continuous cycling at $5 \mathrm{~Hz}$ ) does not influence the plastic strain. However, fatigue loading at $5 \mathrm{~Hz}$ from the start under a loading ramp of $\mathrm{N}_{\mathrm{A}}=100$ significantly reduces the plastic strain for the identical stress amplitudes. In addition, it can be seen that the plastic strain amplitudes continue to rise in the deformed specimens after reaching the preselected maximum stress amplitude (after 100 cycles). The fatigue response of the deformed Ta differs markedly from that of the recrystallized material, the plastic strain being considerably smaller for comparable stress amplitudes. Again, no cyclic hardening or softening can be noticed. The plastic strain behavior of recrystallized Mo is similar to that of the deformed Ta; the plastic strain remains constant after reaching the constant stress level. In the present tests the limit of the resolvable plastic strain range was about $3 \times 10^{-6}$. 

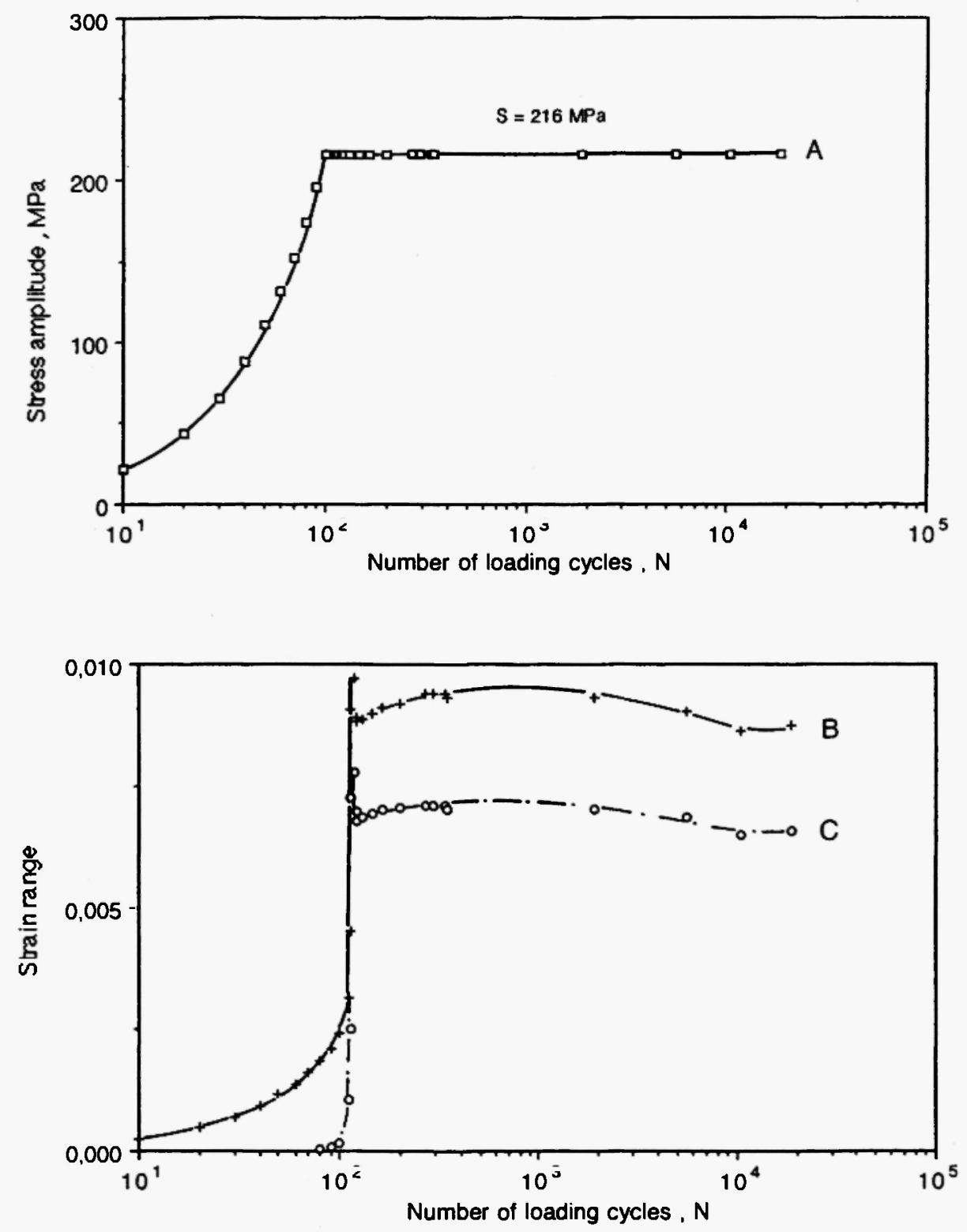

Fig. 3: Loading-N curve (A) and associated total strain curve (B) and plastic strain curve (C) for recrystallized Ta exposed to a cyclic stress of $216 \mathrm{MPa}$ 


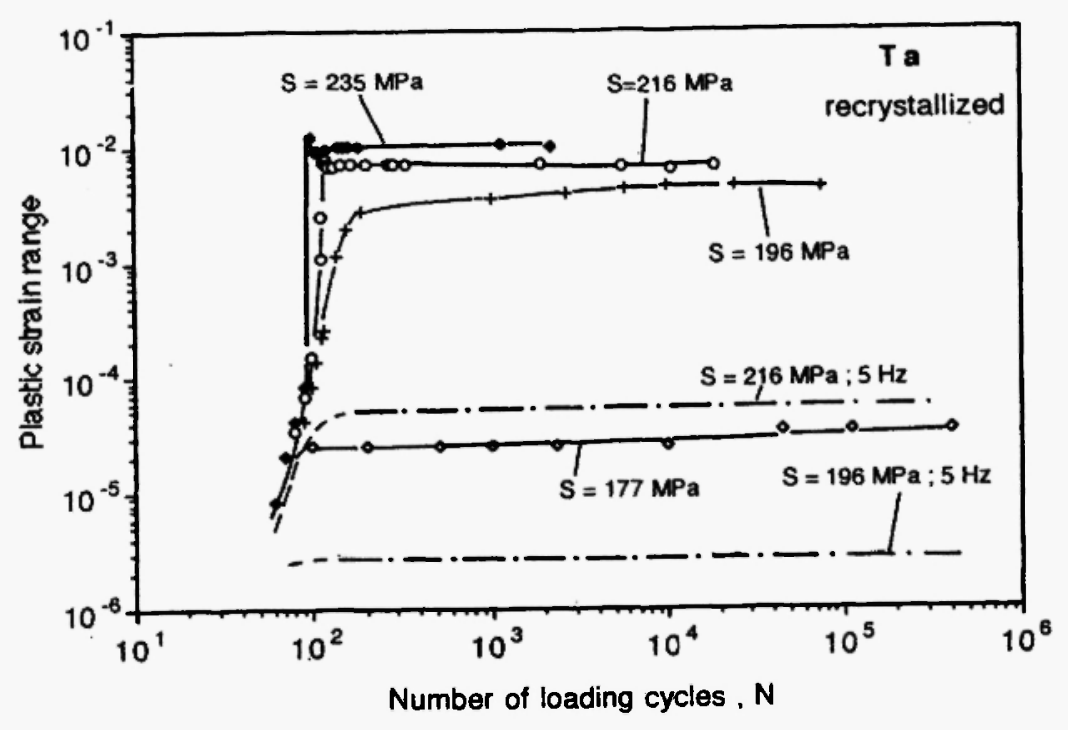

Fig. 4a: Cyclic response of recrystallized Ta specimen for different stress amplitudes tested at $0.05 \mathrm{~Hz}$ and $5 \mathrm{~Hz}$

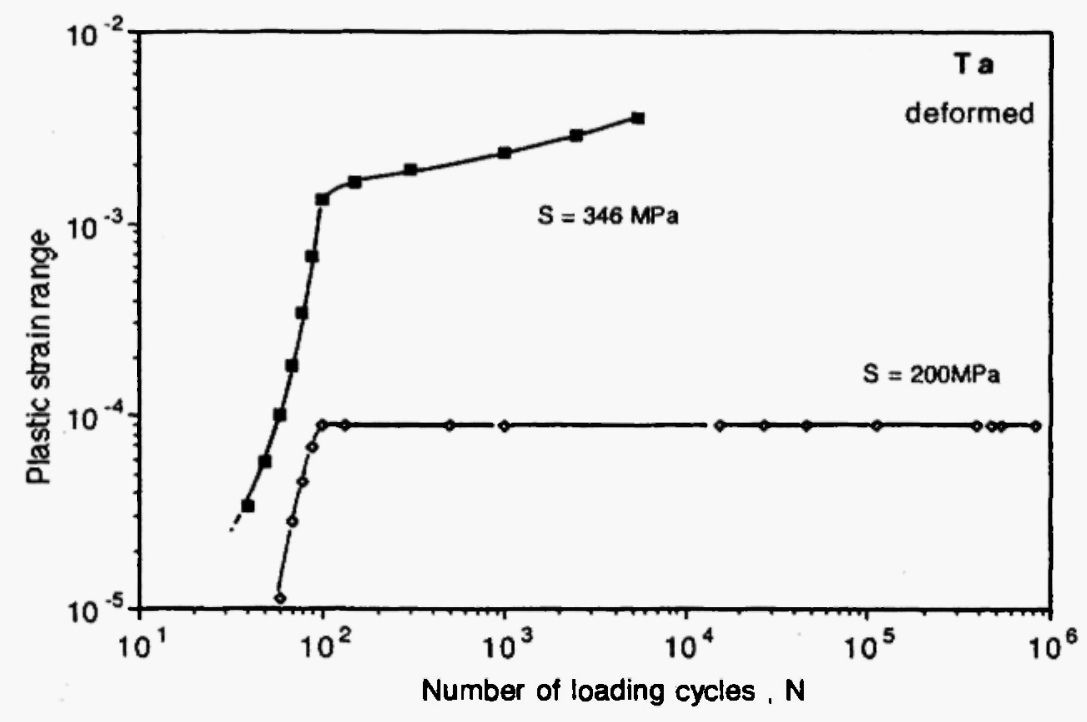

Fig. 4b: Cyclic response of deformed Ta specimens for different stress amplitudes tested at $0.05 \mathrm{~Hz}$ and $5 \mathrm{~Hz}$ 


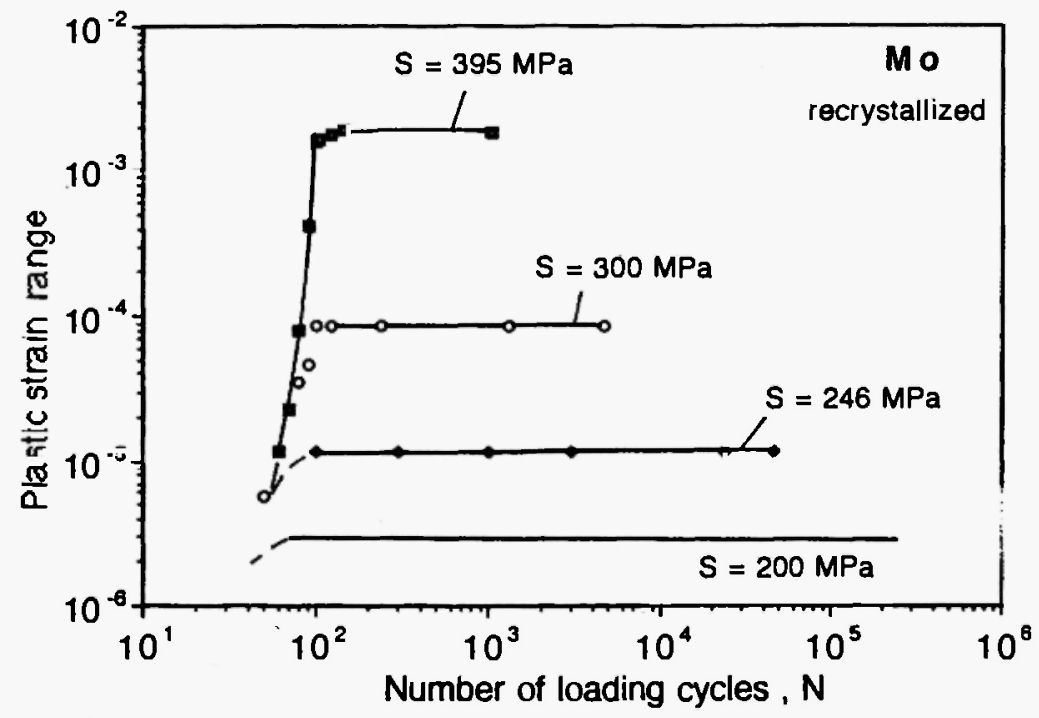

Fig. 4c: Cyclic response of recrystallized Mo specimens for different stress amplitudes tested at $0.05 \mathrm{~Hz}$ and $5 \mathrm{~Hz}$

The cyclic induced creep of recrystallized Ta-specimens under the selected test conditions is significant. As shown in Fig.5 the creep strain increases after reaching the preselected constant stress amplitude (after 100 cycles) only to level off after more than 300 loading cycles. The reasons for this large creep strain could not be identified, but may be related to the asymmetry in the cyclic response under tension and compression, $(1,8)$. In contrast, no measureable creep strain under comparable test conditions could be detected for specimens of deformed $\mathrm{Ta}$ or stress-relieved Mo.

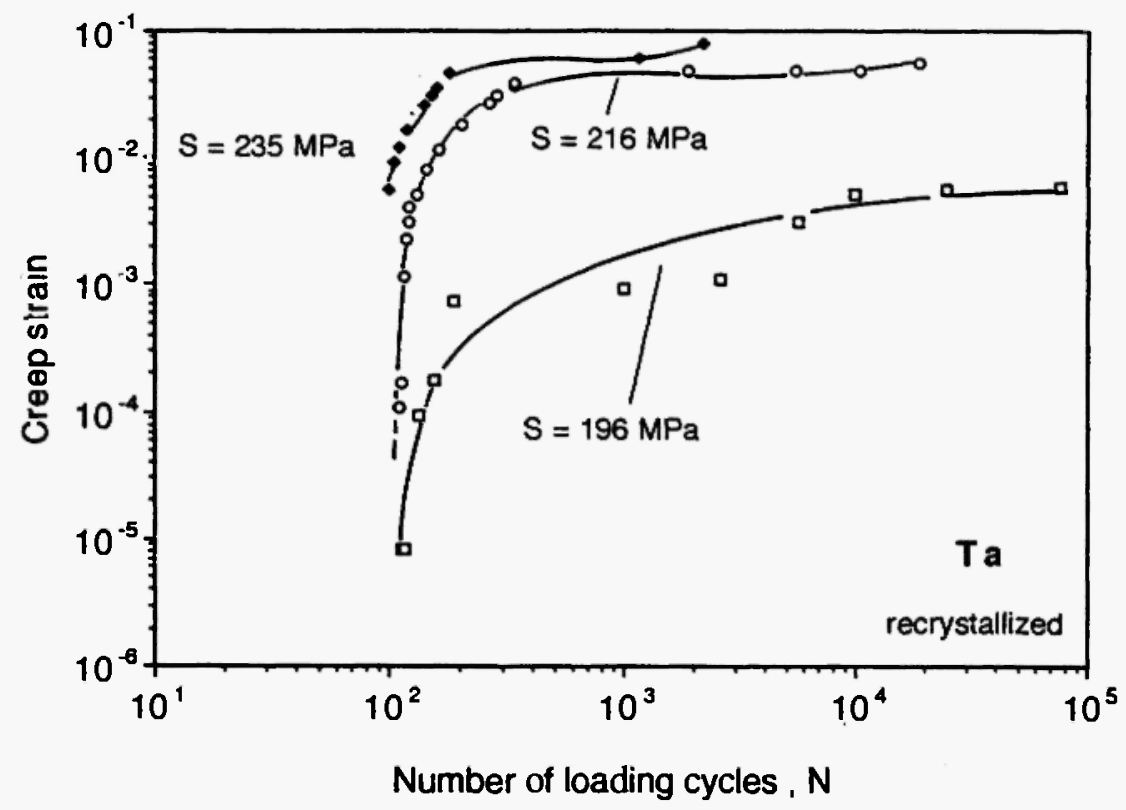

Fig. 5: Cyclic creep strain for recrystallized Ta tested at $0.05 \mathrm{~Hz}$ for various stress amplitudes and a loading ramp of $\mathrm{N}_{\mathrm{A}}=100$ 
On the basis of the saturated plastic strain values deduced from the cyclic plasticity curves it is possible to define cyclic stress strain curves, as shown for deformed and recrystallized Ta and recrystallized Mo specimens in Figs. 6a and 6b, respectively, for test frequencies of $0.05 \mathrm{~Hz}$ and $5 \mathrm{~Hz}$. It is interesting to note an indication of a microplastic plateau for the Ta specimens tested under $0.05 \mathrm{~Hz}$ at stress amplitudes smaller than approx. $200 \mathrm{MPa}$. An increase of the test frequency to $5 \mathrm{~Hz}$ results in a shift of this curve to lower plastic strain values. Such a microplastic plateau has been related to the existence of a fatigue limit in bcc metals (8). For Mo specimens a marked effect of test frequency is noted, a plateau cannot be deduced within the resolvable plastic strain range.

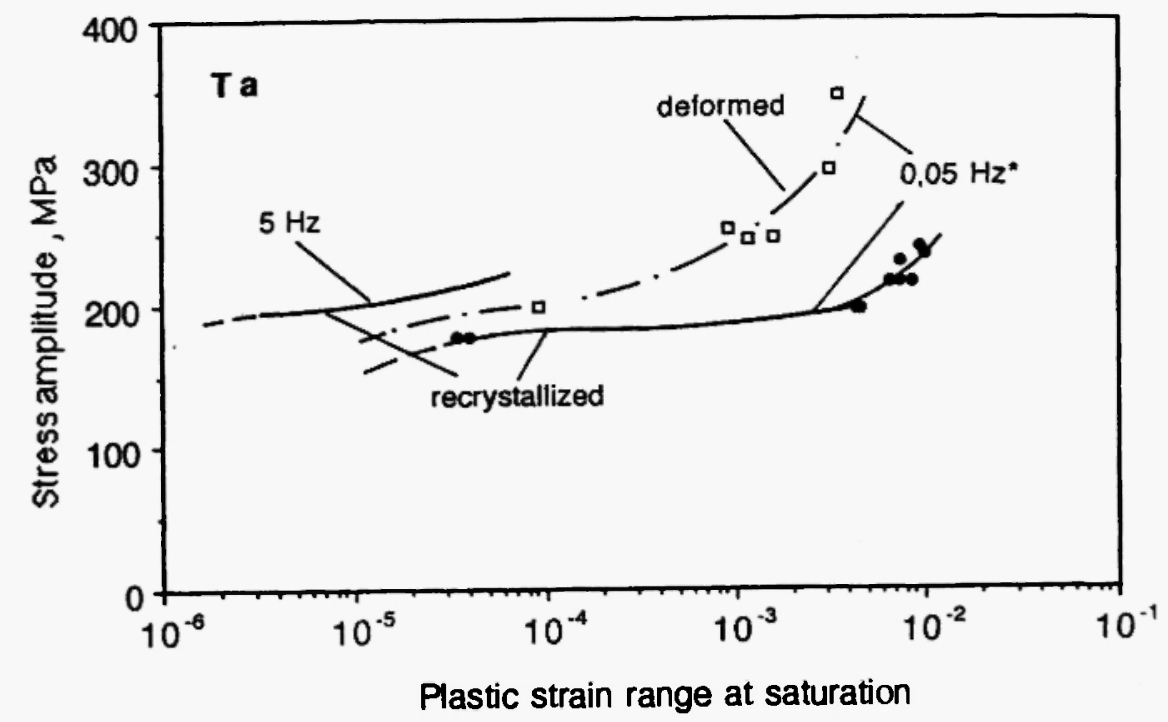

Fig. 6a: Cyclic stress strain response of deformed and recrystallized Ta specimens tested at two cyclic frequencies

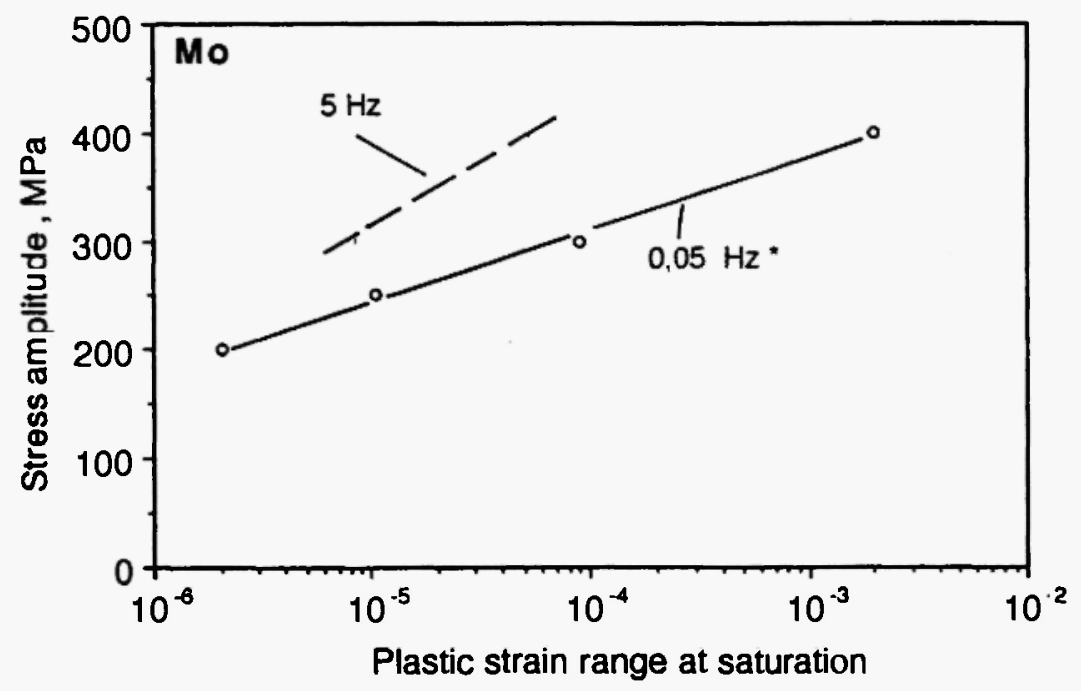

Fig. 6b: Cyclic stress strain response of stress-relieved and recrystallized Mo specimens tested at two cyclic frequencies 
Based on the obtained test results, Coffin-Manson type plots (log epl vs. log NB) were established for both specimen materials, Fig. 7. The preliminary diagrams indicate a straightline relationship down to small plastic strain amplitudes.

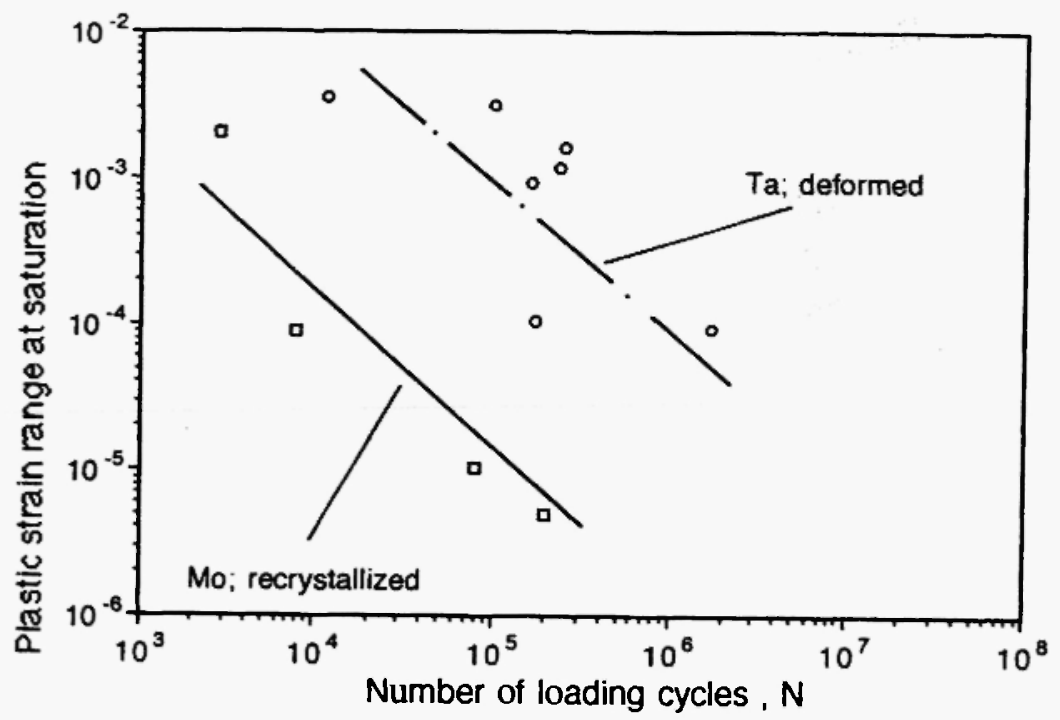

Fig. 7: Coffin-Manson plots for recrystallized Mo and deformed Ta specimens

The marked reduction of the plastic strain range with increasing test frequency may be explained on the basis of the published relationship between the thermal portion of the flow stress and the test temperature as well as strain rate below a critical temperature (1).

In the present study the cyclic experiments were conducted under stress control, whereas most basic investigations of the fatigue response are carried out under total strain or plastic strain control. For steel specimens it had been stated (2) that independent of the control of the cyclic loading (stress or plastic strain control) approximately the same cyclic stress-strain curves may be obtained. Based on our findings of large creep strains associated with the cyclic loading of recrystallized Ta specimens, it may be questionable to apply such an analogy. Nevertheless, engineering applications frequently involve cyclic exposure under load control.

The obtained test results appear to have important engineering implications. As already pointed out by Meiniger and Gibeling (8), the practical understanding of fatigue in bcc metals is based on the concept of a fatigue limit. Most fatigue tests are conducted at high strain rates while service conditions may impose much lower strain rates for which the intrinsic material behaviour is different. It appears necessary, therefore, to reconsider the concept of fatigue behaviour of bcc metals, in particular of the pure high-melting point metals and alloys, in light of the fundamental effects of strain rate, solute content, critical temperature and test temperature on dislocation mobility. 


\section{CONCLUSIONS:}

From the experimental results the following conclusions may be drawn:

- A considerable difference is revealed by the stress-controlled tests between the cyclic behaviour of recrystallized and deformed Ta and Mo materials

- No fatigue softening or hardening was observed for the investigated materials, however, in the recrystallized materials a significant stress dependence of the plastic strain can be noticed

- An increase in test frequency from $0.05 \mathrm{~Hz}$ to $5 \mathrm{~Hz}$ leads to a significant reduction of the plastic strain of the recrystallized materials, which is associated with an increase in fatigue strength

- Under the ramp loading employed in the present study, the cyclic plastic strain in recrystallized Ta is associated with a considerable cyclic assisted creep strain. This has not been observed with recrystallized Mo, which may be taken as an indication of a higher impurity content or only a partially recrystallized microstructure.

- The microplastic plateau observed in the cyclic stress-strain curves for recrystallized Ta may be taken as an indication of the existence of a fatigue limit.

- The presented results may permit a speculation that in addition to the effect of impurities a higher concentration of dislocation may shift the critical temperature to lower values.

- As a consequence of the experimental results precautions should be applied in comparing test results from different fatigue test procedures and materials of differing impurity contents.

\section{ACKNOWLEDGEMENTS:}

The test equipment for the fatigue experiments was gratefully provided by a grant of the Jubiläumsfond der Österreichischen National Bank Vienna (project no. 4394). The authors thank Mr.J.Femböck (Metallwerk Plansee $\mathrm{GmbH}$ ) for valuable comments. 


\section{LITERATURE:}

1. H.Mughrabi et al, Cyclic deformation and fatigue behavior of $\alpha$-iron mono- and polycrystals, Int.J.Fracture 17 (1981) 193

2. D.Eifler, Zusammenhang zwischen Mikrostruktur und Schwingfestigkeitsverhalten bei Stählen, in "Ermüdungsverhalten metallischer Werkstoffe", D.Munz, Ed., DGM Informationsgesellschaft Verlag, Oberursel, 1985, p.73

3. K.Pohl et al, in "Proc.2nd Internat.Symp. on Defects, Fracture and Fatigue", G.C.Sih, Ed., Nijhoff Publ., Den Haag, 1983, p.147

4. M.Werner, Temperature and strain rate dependence of the flow stress of ultrapure Ta single crystals, phys.stat.sol (a) 104 (2987) 63

5. M.Werner and A.Seeger, Temperature and strain-rate dependence of the flow-stress of bcc transition metal crystals in cyclic deformation, in "Proc.ICSMA-8", P.O.Kettunen et al, Eds., Pergamon Press Oxford, 1988, p.173

6. H.Hödl et al, Einfluß der Verformungsgeschwindigkeit auf die Zugfestigkeitseigenschaften von Mo-Blech bei Raumtemperatur, Plansee-Bericht 91MPW-B12a, 31.Dez.1991

7. Chr.Stickler et al, Einfluß der Verformungsgeschwindigkeit auf die Zugfestigkeitseigenschaften von Blechen aus rein-Ta und Ta-2.5\%W bei Raumtemperatur, Plansee-Bericht MPW91-B11, 8.12.1991

8. J.M.Meininger and J.C.Gibeling, Low-cycle fatigue of $\mathrm{Nb}$ and $\mathrm{Nb}-1 \% \mathrm{Zr}$ alloys, Met.Trans.A 23A (1992) 3077

9. Kong Sa et al, The influence of the loading ramp on the cyclic stress-strain response of polycrystalline $\mathrm{Cu}$-specimens, Fatigue 93, J.P.Bailon, Eds., in print 